\title{
Effectiveness of pads and enclosures as safety interventions on consumer trampolines
}

\author{
Keith Alexander, ${ }^{1}$ David Eager, ${ }^{2}$ Carl Scarrott, ${ }^{3}$ George Sushinsky ${ }^{4}$
}

'Department of Mechanical Engineering, University of Canterbury, Christchurch, Canterbury, New Zealand ${ }^{2}$ Faculty of Engineering and Information Technology, University of Technology, Sydney, Australia ${ }^{3}$ Department of Mathematics and Statistics, University of Canterbury, Christchurch, New Zealand

${ }^{4}$ Retired from US Consumer Product Safety Commission (CPSC), Washington, DC, USA

\section{Correspondence to}

Dr Keith Alexander, Department of Mechanical Engineering, University of Canterbury, Christchurch, Canterbury, PB 4800, New Zealand: keith.alexander@canterbury.ac.nz

Accepted 29 November 2009

\begin{abstract}
Background Trampolines continue to be a major source of childhood injury.

Objective To examine available data on trampoline injuries in order to determine the effectiveness of padding and enclosures.

Design Trampoline injuries from the NEISS database from 2002 to 2007 were reclassified into five causecategories, to examine evidence for injury trends.

Setting The ASTM trampoline standard recommendations for safety padding were upgraded in 1999 and enclosures were introduced in 1997. This is the first study to examine the impact of these changes. Patients The sampling frame comprises patients with NEISS product code 'consumer trampolines' (1233). A systematic sample of 360 patients each year is taken. Interventions The prominent interventions recommended by the ASTM are netting enclosures to prevent falling off and safety padding to cover frames and springs.
\end{abstract}

Main outcome measures Proportion of injuries within each cause-category and trend estimates.

Results There was no evidence for a decline within the injury cause-categories that should be prevented by these interventions from 2002 to 2007.

Conclusions If these interventions were effective the associated injury causes would be in decline. Instead they remain close to half of all trampoline injuries with no significant change over the period of the study. Follow-up studies are proposed to determine the reasons. Given the number of injuries involved it is recommended that steps be taken to ensure these safety interventions or their equivalents are in place, work properly and remain effective for the life of consumer trampolines.

\section{INTRODUCTION}

The purpose of this study is to examine US injury data for consumer trampolines in order to determine whether the recommended safety interventions in the standards are having the intended effect. ${ }^{12}$ Of particular interest is the efficacy of safety pads that cover the frame and springs, and boundary net enclosures that prevent children from falling off. While this study is derived from trampoline injuries in the USA, it will be a reference point for other countries.

This project draws on the US National Electronic Injury Surveillance System (NEISS) online database, managed by The US Consumer Product Safety Commission (CPSC). ${ }^{3}$ For the period of this study the NEISS annual reports have shown an increase from 89360 emergency department presentations in 2002, rising to 111850 in 2004 and settling back to 107435 in 2007. These figures, extrapolated from datasets of around 3000 are reported to have a SE of $8 \%{ }^{3}$

Past studies of trampoline injuries have focused on the overall annual rate and types, ${ }^{4} 5$ though some have identified causes as well. ${ }^{6}$

Those involved in the industry, such as the International Trampoline Industry Association (ITIA), being sensitive to these studies have endeavoured to deliver safer products: in 1998 after calls by the American Association of Pediatricians to ban consumer trampolines because of the rising injury rates, ${ }^{6-8}$ CPSC met with the ITIA and the American Society of Testing and Materials (ASTM) Trampoline Subcommittee, F08.17, and agreed on upgraded safety requirements in the standard. ${ }^{9}$ The improvements appeared in the 1999 revision to the standard. ${ }^{10}$ In summary, these improvements comprised:

- Prominent warnings advising against somersaulting and multiple jumpers.

- Extended padding to fully cover both frame and springs.

- Specific measures to retain padding and to ensure it survived impacts.

- No access for children under 6 years of age, and the prohibiting of ladders packaged with trampolines, to limit unsupervised access by children under 6.

In 1997 developments began, and in 2001 patents were granted for enclosures to prevent people falling off trampolines. ${ }^{11} 12$ Subsequently enclosures began appearing in the market, and in 2003 the ASTM Trampoline Subcommittee produced a new standard for trampoline enclosures. ${ }^{13}$ Figure 1 depicts a deteriorating enclosure, less than 3 years old, on a trampoline where the pads have deteriorated to the extent that they have been removed.

Given that these two safety interventions were upgraded or begun over 10 years ago, the question to be addressed is: Are these interventions working? To date no studies have assessed their effectiveness.

Several issues make it difficult to see whether improvements have been reducing injuries:

- Changes in sales have masked the effects of improvements.

- Trampoline lifetimes have been reducing as manufacture has shifted offshore and costs have been cut. (ITIA estimated trampoline life in 1989 at about 10 years, but this had reduced to 5 years by 2004; personal communication with Lani Loken, ITIA executive, 2005).

- It is possible that trampoline usage patterns have changed over 10 years.

The procedure used in this study avoids these difficulties by looking at the relative proportions of unlocked scheme, see http:// Injuryprevention.bmi.com/site/ about/unlocked.xhtml 


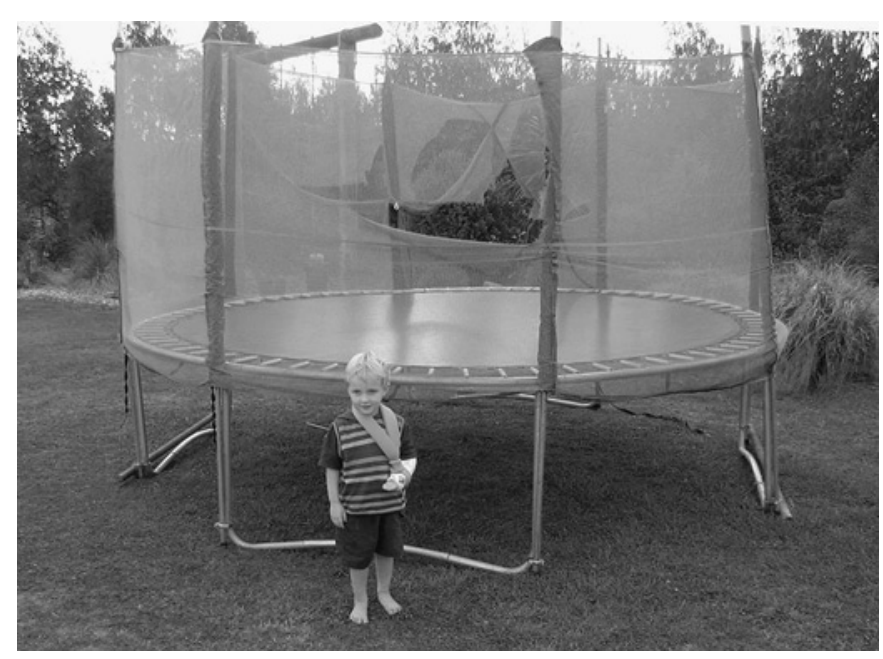

Figure 1 A typical consumer trampoline and enclosure after less than 3 years of use. The pads have deteriorated and been removed, the enclosure net is torn. The subject bounced through the hole in the net and fell to the ground, fracturing his wrist (with permission from $\operatorname{Dr} S$ Gooch, University of Canterbury, New Zealand).

specific injury causes, tracking them over time to ascertain whether unwanted injury causes are in decline. For example, if enclosures were becoming widespread and stopping children falling off, then over the period 2002 to 2007 a decline would be expected in the proportion of falling-off injuries.

\section{METHODS}

\section{Effectiveness of pads and enclosures from 2002 to 2007}

This section examines cases from the NEISS database, assigning each case to an injury cause-category.

The NEISS trampoline data for each year consists of between 1994 and 3299 cases $^{i}$ offering a variety of injury information, but little that is specific enough to apply to the design of trampolines. However, since 2002 the database has included brief narratives giving commentary on each case. For this study, 360 case records were randomly selected from each year from 2002 to 2007. Using the narratives, the cases were allocated into the following five cause-categories, useful in assessing safety interventions and user behaviour:

1. Injuries the jumper causes to him or herself, on the trampoline mat ('hurt myself').

2. Falling off, on to the ground ('falling off').

3. Impact with the frame or springs ('frame and springs').

4. Multiple jumpers on the trampoline at the same time ('multiple jumpers').

5. Injuries while getting on or off the trampoline ('getting on and off').

Pads should prevent contact with the frame and springs, and enclosures should stop people falling off. However, in order to give a full picture that includes user behaviour, all five causecategories have been examined.

Protocol for sorting cases into the five cause-categories

For most case narratives the cause-category was easily assigned, but for about one third there was some ambiguity. To allow for

'NEISS sample sizes: 2002 ( $N=2549), 2003$ ( $N=2849), 2004$ ( $N=3277), 2005$ $(N=3299), 2006(N=3224), 2007(N=1994)$. this, seven 'combination categories' were generated to gather these ambiguous cases. The combination categories were:

- Hurt myself/frame and springs.

- Hurt myself/frame and springs/multiple jumpers.

- Hurt myself/frame and springs/fell off.

- Hurt myself/fell off.

- Frame and springs/fell off.

- Frame and springs/multiple jumpers.

- Hurt myself/frame and springs/fell off/multiple jumpers/ getting on and off.

An eighth category captured irrelevant cases, and excluded them from the analysis. These were cases such as: 'patient rode mountain bike into trampoline leg; fractured wrist'. Consequently case numbers for each year varied somewhat. ${ }^{i}$

At the conclusion of the sorting process the contents of the combination categories were randomly shared between the individual categories concerned, in proportion to the final category sizes. Though simulation studies such as multiple imputation methods were considered for this allocation process, they were discounted because the trends, already insignificant (shown below) would be even less significant with the increased variability that these methods would introduce.

\section{Determining diagnosis types in each category}

Each NEISS case record includes the diagnosis (or injury description) given by the emergency department. There are 30 diagnosis options available, but nine were selected as contributing to this study ${ }^{\text {iii }}$ (for example, 'drowning' was not relevant), with a tenth designated as 'all others'. ${ }^{14}$ Once cases were assigned to a cause-category, totals were found for each of the nine diagnoses, as shown in figure 2.

\section{Uncertainties within the data}

- The 95\% CIs in figure 3 were calculated for each causecategory, using central limit theorem estimates. As evident from the interval size, the sample size was sufficiently large.

- The effect of experimenter decision strategy in allocating cases could have changed the relative sizes of categories. To minimise this:

-The same experimenter categorised all cases.

-The years were processed out of sequence $(01,07,02,06$, 03, 05, 04).

-For consistency testing, a pilot sorting process was performed for all years, using different sets of randomly selected cases, then the results compared.

- With consistent application of the decision strategy there should be no effect on trends. Again the results of the pilot sorting process were compared with the current results to check that trends over time did not change.

\section{Warranty information}

To obtain some indication as to why the interventions do not seem effective, warranty information was examined from users' manuals for leading manufacturers of trampolines in the USA before 2004, this period being relevant to trampolines to 2007. The warranty periods for components of interest were found, weighted by manufacturer market-share ${ }^{\mathrm{iv}}$ and averaged

\footnotetext{
ii Study sample sizes: 2002

( $n=324), 2003$ ( $n=346), 2004$ ( $n=353), 2005$ ( $n=343), 2006$ ( $n=348), 2007$ $(n=331)$.

iii NEISS diagnosis codes in figure 2: $57,64,53,59,71,62,60,55,52$.

iv Market share for 2002 to 2004 was obtained verbally from Lumex, who sold mat fabric during that period.
} 


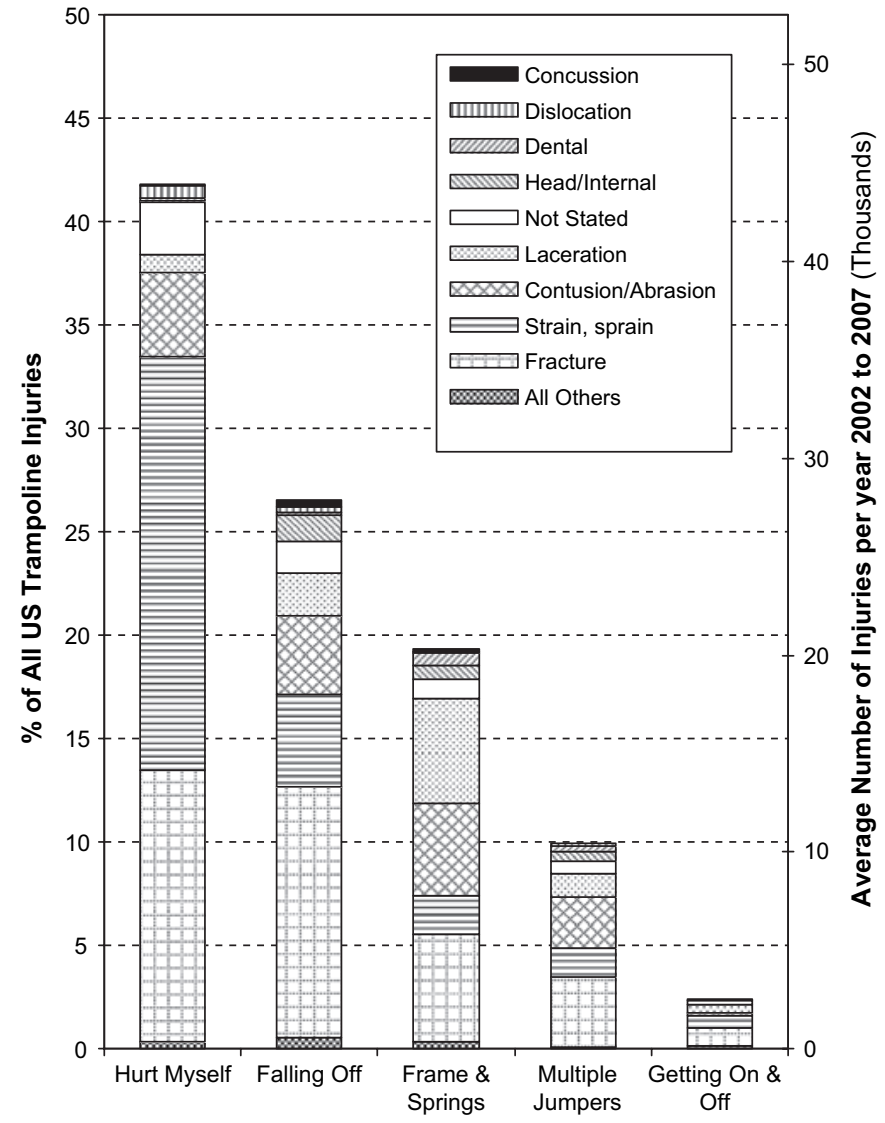

Figure 2 Analysis of NEISS data averaged from 2002 to 2007, in cause-categories useful for the evaluation of specific injury prevention measures.

(see table 1). For comparison, present day warranty information was averaged from current websites.

\section{RESULTS}

\section{Effectiveness of pads and enclosures from 2002 to 2007}

The allocation proportions in the five cause-categories are shown in figures 2 and 3 . Figure 3 includes an estimated trend in the proportions in the key cause-categories over the study period. Figure 2 shows the average of all 6 years and includes proportions of the injuries themselves. Results by category follow.

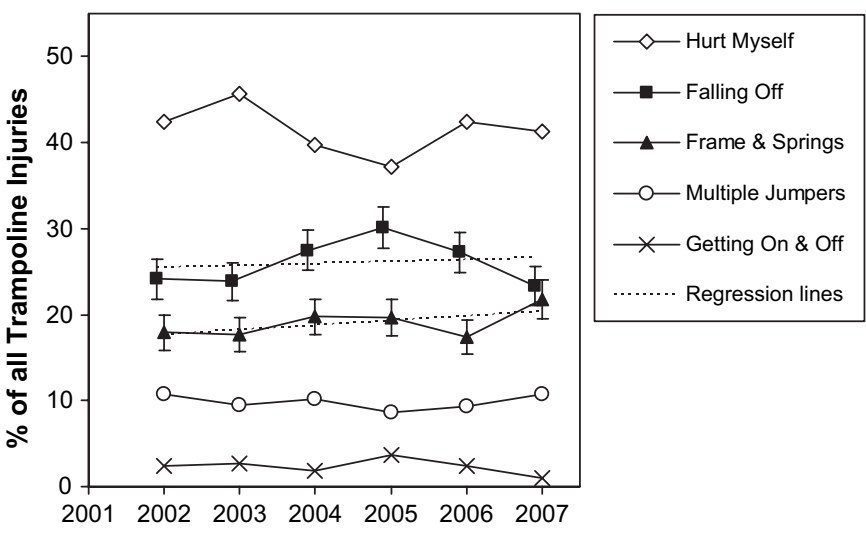

Figure 3 Relative proportions of the five injury cause-categories with time. Simple linear regression estimates are shown for 'falling-off' and 'frame and springs' categories; 95\% Cls are shown.
Table 1 Warranty information sourced from manufacturer's user manuals and websites

\begin{tabular}{lll}
\hline & \multicolumn{2}{l}{ Average warranty period $(\mathbf{y})$} \\
\cline { 2 - 3 } & Before 2004 & Present day \\
\hline Frame & 9.9 & 5.1 \\
Mat & 4.9 & 2.8 \\
Pads & 0.52 & 0.8 \\
Enclosure net & 0.25 & 0.53 \\
References & $16-20$ & $21-27$ \\
\hline
\end{tabular}

Hurt-myself injuries

This is the largest cause-category where, for example, the jumper sprained a wrist or ankle landing badly on the trampoline mat or pads. Figure 2 shows that this 'hurt-myself' category results in about $42 \%$ of injuries, primarily strains and sprains, though there are also a number of fractures, shown in the database to be typically wrists, ankles, elbows and fingers.

\section{Injuries from falling off}

In the 'falling-off' category cases were primarily selected where the narratives noted specifically that the jumper had fallen on to the ground or some object on the ground. This category consists of over $27 \%$ (1.9\%) of all trampoline injuries (figure 2). It results primarily in fractures, then contusions, sprains and lacerations as well as the largest number of head injuries of any category. Figure 3 shows that falling-off injuries have varied somewhat but clearly shows no significant change in the 6 years of the study, with little scope for a downward trend, even if the sample information was increased. A formal trend test gave an estimated increase per year of $0.25 \%(0.57 \%)$ (ie, opposite to the expected direction), demonstrating the lack of statistical significance for any downward trend over the 6 years. While the 3 years from 2005 to 2007 show a decreasing trend, it is too early to draw a conclusion.

\section{Injuries from the frame and springs}

The 'frame and springs' category is made up of cases where the NEISS narrative makes specific mention of frame or spring components. This category comprises just over $19 \%$ (1.7\%) of all trampoline injuries and involves fractures, lacerations and contusions, as well as dental and head injuries. Figure 3 shows insufficient evidence for a change in this category since 2002, shown by substantial overlap in CIs and confirmed by a formal trend test again giving an estimated increase, in this instance of $0.52 \%(0.51 \%)$ per year.

\section{Injuries from multiple jumpers}

In this category the narrative specifically mentions other jumpers, for example '... brother fell on patient's arm and patient heard a crack'. This category comprises $10 \%$ of all trampoline injuries and involves fractures, contusion, sprains, lacerations and closed head injuries.

Injuries from getting on and off

This category is small (just more than $2 \%$ of injuries) but is of note since the standard forbids the sale of ladders as part of the trampoline package.

\section{Warranty information}

Typical warranty information is shown in table 1, along with its source references. The warranty period for safety pads and enclosure nets can be seen to be much less than that of the frame and mat, showing that the manufacturers expect these safety 
features to be disposable items that should be replaced during the life of the trampoline.

\section{DISCUSSION}

\section{Trends in safety intervention effectiveness over time}

The results in figures 2 and 3 show that falling-off and frame and springs cause-categories together account for $46 \%(2.2 \%)$ of injuries, and since 2002 there has been little or no change to the proportion of injuries that safety pads and enclosures are designed to reduce.

The paper by Furnival et al, covering the period 1990 to 1997, before enclosures were invented, reports that $28 \%$ of injuries were caused by falling off, and fractures were more frequently associated with falling off than with other causes. ${ }^{6}$ The results from the present study are substantively the same: $27 \%(1.9 \%)$ of injuries caused by falling off with almost the largest share of fractures. This suggests that for falling-off injuries at least, there has been no measurable change since the mid-1990s.

This trend data is robust, with a formal trend test confirming that even with sampling variability taken into account, there is little scope for a decreasing trend, even if sample information was increased. The trend is also supported by the previous research noted. ${ }^{6}$

While there is a hopeful drop in falling-off injuries from 2005 to 2007 , until it is shown to continue in future years it remains statistically insignificant.

\section{Other injury cause-categories}

The two categories resulting from user behaviour are the 'hurtmyself' and 'multiple-jumpers' categories. The largest at $42 \%$, the hurt-myself category is not attributable to design failure or safety interventions, but occurs with proper use of trampolines and is to be expected like many other childhood injuries, where children engage with:

\section{"...a stimulating environment which presents...users with manageable challenges, through which they can find and test their limits." 28}

The multiple-jumpers category $(10 \%)$ similarly is not attributable to design or interventions but results from the users' choice to ignore the 'one at a time' rule in the warnings that should be visible on the trampoline. ${ }^{10}$

\section{Strengths and weaknesses of this study}

The strength of this study is that it draws on a large, and consistently maintained, longitudinal database, with enough data that injury-cause proportions can be tracked over time. This allows it to be independent of market fluctuations, and provides a unique ability to focus on the effectiveness of interventions.

The weakest area of the work is its dependence on experimenter decision-making in assigning several thousand brief narratives of greatly varying information quality, into appropriate categories. While trend information remains consistent, a decision bias could affect the relative sizes of the categories in figure 2. The falling-off and multiple-jumpers categories were clear, but a different experimenter might conclude with slightly different proportions shared between the hurt-myself and frame and springs categories.

\section{Mechanisms}

The analysis of NEISS data does not show why these interventions are not effective. The reasons are not yet known and are open for discussion. The authors however wish to introduce alternative information suggesting where the faults might lie. Two possible reasons might be given for this failure.
First, it has been proposed that the safety interventions recommended by the standards simply do not work. While the performance requirements in the upgraded standards of 1999 and 2001, and the enclosure standard introduced in 2003 might be expected to result in good safety interventions, their effectiveness in real world settings has yet to be confirmed in a controlled study. ${ }^{101315}$

Second, it has been proposed that the safety interventions fail simply because they are not there. A number of contributing reasons for this might be:

- The standards are being ignored and non-compliant trampolines are being sold without these safety features (eg, compliance is not mandatory).

- The standards do not require full compliance (the standards do not require, for example, that a trampoline must have an enclosure).

- Standards-compliant trampolines are being sold, but it is easy for them to be assembled and used without these safety features in place.

- Trampolines are compliant at the point of sale and these interventions are installed. Initially they work, but then they deteriorate quickly and are not replaced (this is the case in figure 1 and is consistent with warranty information in table 1).

- It is taking time for standards-compliant trampolines to replace old non-compliant trampolines.

\section{Future research}

These proposals suggest two follow-up studies:

1. A study to confirm real world effectiveness of the safety pads and enclosures recommended by the standards.

2. A study to find out whether or not pads and enclosures are in place when injuries occur. This might be done by arranging to contact the injured patients to query them about the safety features of their trampolines at the time of injury.

\section{Implications of the findings of this study}

It would have to be concluded that the advent of enclosures in 1997 and the ASTM standards upgrades in 1999 to improve padding, have to this point made no measurable change to trampoline injury statistics. Whatever has been done is not yet working. If the 2008 NEISS Injury Report shows no improvement, there will be an even stronger case for doing things differently.

The way forward is open for debate but it could include several of the following components:

1. Undertake the follow-up studies suggested above to identify the reasons for failure.

2. Upgrade the standards so that their recommended safety features are proven in real world settings, and survive for the life of the product.

3. Consider controls on sales such as mandatory standards compliance.

4. Challenge retailers and manufacturers to excel in providing safe designs rather than competing on price.

5. Arrange for some authority to report annually on the injury statistics, using methods of this study, to gauge progress in the cause-categories of interest.

\section{CONCLUSIONS}

This paper shows that in spite of additional safety interventions on consumer trampolines initiated in 1997 and required by the standards in 1999, the expected reductions in the relevant injury categories have not materialised. The result is that around $27 \%$ 


\section{What is already known on the subject}

- Injuries from consumer trampolines have been rising for as long as records have been kept but seem to have leveled off at about 105,000 per year.

- Sales have also been changing, masking the effect of upgraded trampoline standards.

- Better safety interventions recommended by the standards since 1999 are appearing on trampolines in the market.

\section{What this study adds}

The safety interventions recommended by the standards are having a minimal effect with no change measurable over the period of the study.

- The reasons for this failure or not known.

- Proposed follow-up studies should start to address this by determining whether the recommended interventions work, and whether they are in place on trampolines.

$(1.9 \%)$ of injuries are still the result of children falling off, and $19 \%(1.7 \%)$ are still from impacts with frames and springs. It will be interesting to see if what looks like a decline in falling-off injuries from 2005 to 2007 continues as more data comes to hand, but at this point no conclusions can be drawn.

While the reasons for lack of effectiveness of the interventions have not been established, two suggested questions for followup studies are:

1. Do the safety pads and enclosures recommended by the standards work effectively?

2. Are the safety pads and enclosures in place on the trampolines causing injury, or are they simply not there?

Because whatever has been done since 1999 is not working, suggestions are offered for effective progress.

Given the potential benefits, it is strongly recommended that steps are taken to ensure that these safety interventions, or their equivalents, are in place, work properly and remain effective for the life of consumer trampolines.

Competing interests Three of the authors of this paper are closely interconnected with organisations that will be affected by the paper. One reason for the collaboration has been to ensure some balance. Nevertheless potential conflicts of interest are listed in order of importance below. KA is the inventor of the Springfree trampoline and has a minor financial interest in the company now manufacturing it. The Springfree trampoline is arguably better designed to prevent the injuries that the paper highlights, than others on the market. This author could be said to have a vested interest in publishing this paper; KA is also a member, and the minutes secretary of the ASTM subcommittee F08-17, 'Trampolines and Related Equipment'. This paper has the potential to direct strategy for that committee. DE undertakes testing of trampolines for compliance with the Australian Trampoline standard, AS4989, and is also on the committee responsible for review of that standard. Results from this paper could theoretically contribute to this standard and consequently to DE's testing work $\mathrm{DE}$ is currently undertaking a funded project to investigate the safety record of Springfree trampolines in the Australian market. This could potentially bias his views on this paper. DE, GS and KA are all members of the ASTM subcommittee F08-17, so potentially they could form a group controlling the committee. GS has recently retired from the Consumer Product Safety Commission (CPSC), the US government organisation responsible for the database used in the paper. CS has no competing interests but has become involved as a statistician.

Patient consent Obtained

Provenance and peer review Not commissioned; externally peer reviewed.

\section{REFERENCES}

1. US Standard. ASTM F381-06 Standard Consumer Safety Specification for Components, Assembly, and Use of a Trampoline. 2006.

2. US Standard. ASTM F2225-09 Standard Safety Specification for Consumer Trampoline Enclosures. 2009

3. NEISS database. http://www.cpsc.gov/LIBRARY/neiss.html laccessed 10 May 2009).

4. Chalmers DJ, Hume PA, Wilson BD. Trampolines in New Zealand: A decade of injuries. Br J Sports Med 1994;28:234-8.

5. American Academy of Pediatrics Committee on Injury and Poison Prevention and Committee on Sports Medicine and Fitness. Trampolines at home, school, and recreational centers. Pediatrics 1999;103:1053-6.

6. Furnival RA, Street KA, Schunk JE. Too many pediatric trampoline injuries. Pediatrics 1999;103:e57 http://pediatrics.aappublications.org/cgi/content/full/103/ 5/e57 (accessed 24 Jun 2009)

7. Smith GA. Injuries to children in the United States related to trampolines, 1990-1995: a national epidemic. Pediatrics 1998:101:406-12.

8. American Academy of Pediatrics. Policy statement. Trampolines II (RE2214). Committee on accident \& poison prevention and committee on pediatric aspects of physical fitness, recreation and sports. Pediatrics 1981;67:438-9.

9. Meeting between ASTM F08.17 Subcommittee and CPSC Office of Compliance. CPSC comments on ballot for F381-95 trampoline standard. http:// www.cpsc.gov/LIBRARY/FOIA/meetings/mtg99/trampoline.pdf (accessed 10 May 2009).

10. US Standard. ASTM F381-99 Standard Consumer Safety Specification for Components, Assembly, and Use of a Trampoline. 1999; (superceded).

11. Publicover MW, Greiner JH, Publicover JS, et al. Trampoline or the like with Enclosure. US Patent 6,261,207, granted in 2000. (accessed 12 Jun 2009).

12. Publicover MW. http://www.jumpsport.com/ourstory.htm laccessed 28 Sep 2009).

13. US Standard. ASTM F2225-03 "Standard Safety Specification for Consumer Trampoline Enclosures", 2003 (superceded).

14. NEISS Coding Manual http://www.cpsc.gov/neiss/completemanual.pdf (accessed 5 Jun 2009) P8.

15. US Standard. ASTM F381-01 Standard Consumer Safety Specification for Components, Assembly, and Use of a Trampoline. 2001; (superceded).

16. User Manual. Jumpking Manual AB14 (without enclosure), copyright 1997.

17. User Manual. Jumpsport Jumpcourt 280 Manual (with enclosure), copyright 2001

18. User Manual. AllyOop Manual (with enclosure), copyright 2002.

19. User Manual. JumpKing Funring Enclosure Manual, copyright 2003.

20. User Manual. Hedstrom Manual (without enclosure) copyright 1995.

21. http://www.jumpsport.com/pr-trampolines-econo.htm (accessed Oct 2009).

22. http://www.samsclub.com/shopping/navigate.do?catg=4648 (accessed Oct 2009)

23. http://www.jumpking.com/warranty.htm (accessed Oct 2009).

24. http://www.airzonetrampolines.com/ (accessed Oct 2009)

25. http://16fttrampoline.com/16-ft-trampolines/16-foot-octagon-magic-cage-trampolineby-magic-circle-trampoline/ (accessed Oct 2009)

26. http://www.1800trampoline.com/trampolinecombos.aspx (accessed Oct 2009)

27. http://www.trampolinepartsandsupply.com (accessed Oct 2009).

28. Australian Standard. AS4989:2006 Trampolines. Foreword. 2006 